\title{
Phenotypic ANd Biochemical PARAMETERs OF Four SWeet Cherries (Prunus A Vium L.) Cultivars Grown in Agro-Ecological Conditions of MiddLe ATlas OF MOROCCO
}

\author{
Mina EI Baji ${ }^{1,2 *}$, Ossama Kodad ${ }^{1}$, Hafida Hanine², Said En-nahli', A Ait Oubahou ${ }^{3}$ \\ ${ }^{l}$ Department of Pomologie, National School of Agriculture- Meknes, Morocco \\ ${ }^{2}$ Laboratory of Bioprocess and Bio-Interfaces, University of Sultan Moulay Slimane, \\ Beni Mellal, Morocco \\ ${ }^{3}$ Agronomic and Veterinary Institute Hassan II, Agadir, Morocco \\ hafidahanine0@gmail.com
}

(Received January 2019 - Accepted July 2019)

\begin{abstract}
El Baji, M. Kodad, O. Hafida, H. and En-nahli, S. Oubahou, A. A. 2019. Phenotypic and biochemical parameters of four sweet cherries (prunus avium 1.) cultivars grown in agro-ecological conditions of middle atlas of morocco. Lebanese Science Journal. 20(3): 363-379.

The objective of this study is to investigate the phenotypic and biochemical parameters of selected sweet cherry (Prunus avium) from middle region of Morocco. The main biochemical composition, contents of total polyphenols, total flavonoids, total anthocyanins and antioxidant activity, were measured in the fruits of four sweet cherry cultivars ('Burlat', 'Van', 'Napoleon' and 'Cerisette') grown in two locations ("Laanoceur" and "Toufselt") in the Middle Atlas. The free radical scavenging activity was evaluated spectrophotometrically using 1,1-diphenyl-2-picrylhydrazine (DPPH) and ABTS assay. The fruit weight, and pulp percentage were studied and found to range between 237-329 g, 38.14-42.22\%, 39.21-44.36 g, and 52.27-57.48\%, respectively.
\end{abstract}

The total phenolic and total anthocyanin content ranged from 305.99 and 306.67 mg EqGal/100g D.W, total flavonoid contents were within the range of 481.73-517.67 mgeqRE/100g D.W, and total anthocyanin contents were between 1.09 and $2.89 \mathrm{mg}$ Eqcyanidin 3-glucoside/100g D.W. Antioxidant activity ranged from 17.18 to $18.11 \mathrm{mg}$ EqTrolox/100g D.W for DPPH assay and from 27.97 to $29.60 \mathrm{mg}$ EqTrolox/100f D.W for ABTS method. The highest values of total anthocyanin content and antioxidant activity (DPPH) were recorded in 'Burlat'. The highest value of total flavonoid content was found in 'Cerisette'. Cherries from "Laanoceur" and "Toufselt" locations are

http://dx.doi.org/10.22453/LSJ-020.3.363-379 National Council for Scientific Research - Lebanon 2018(C) lsj.cnrs.edu.lb/vol-20-no-3-2019/ 
characterized by similar biochemical composition and antioxidant activity, except for total anthocyanin content that shows slightly elevated values in "Laanoceur". The close correlation between total phenolic contents and antioxidant activities $\left(r^{2}=0.73\right)$ show that antioxidant activity of cherry fruit depends on total polyphenols.

Keywords: pomological properties, total phenolic, anthocyanins, sweet cherry, DPPH, diphenylpicrylhydrazyl, free radical, antioxidant activity ABTS, flavonoids.

\section{INTRODUCTION}

Sweet cherry (Prunus avium L.), a fleshy non-climacteric stone fruit belongs to the genus Prunus and is mainly grown in countries with temperate climate. The species is reported to have originated from an area that includes Asia Minor, Iran, Iraq and Syria (Vavilov, 1951). In Morocco, the sweet cherry culture occupies an area of 2000 hectares, with an annual production of 14.100 tones (DRA, 2014). The most popular sweet cherry varieties cultivated in Morocco are 'Bigarreau Van' and 'BigarreauBurlat' (Oukabli, 2004; Kodad et al., 2010) and the cultivars 'Napoleon' used as pollinizer.4 However, there are other varieties cultivated at small scale such as 'Cerisette' and 'Coeur de pigeon'(Oukabli, 2004).We hypothesized that these varieties differ from each other in some physical and biochemical features. Studies for characterization of sweet cherry fruit may have crucial importance for the producers in designing the necessary harvesting and postharvest technology of sweet cherry production in the world (PérezSánchez et al. 2010).

This species presents a great economic importance due to the nutritional, technological and commercial value of the fruits (Pérez-Sánchez et al., 2010).The nutritional importance especially depends on the biochemical composition, which represents a major source of antioxidant compounds (Usenik et al., 2008).It is widely accepted for quality characteristics of the fruits like skin color, texture, sugar content, sourness, and volatile composition (Diaz-Mula et al., 2009).Anthocyanin contents and the ratio of total solids/total acidity (known maturity) are other factors in consumers' acceptance (Martinez-Romero et al., 2006).Anthocyanins are plant pigments that are responsible for the color of many fruits, including sour cherry (Pedisic et al., 2009)and pomegranate (Varasteh et al. 2012).A recent increase in the interest for nutraceuticals has led to select for higher phenolic contents in fruits (Kim et al., 2005). Cherries, in particular, have been found to offer a good source of antioxidants and contain compounds believed to aid in pain relief of arthritis, gout and headaches (Naderiboldaji et al. 2008). Many studies have been conducted to evaluate their properties in terms of quality and bioactivity. (Kim et al. 2005; Hegedüs et al. 2013; Papp et al. 2015).

The antioxidant capacity of cherries is due to the presence of phenolics such as anthocyanin and melatonin (Seeram et al., 2001) Sweet cherries are rich in these types of phenolic compounds (Kim et al. 2005). Because of these phenolics, cherries rank first followed by other 19 fruits when comparing their antioxidant capacity (Vinson et al., 2001). Fresh cherries are rich in anthocyanins, they are responsible of skin color of cherries (Seeram et al., 2001) which is considered the most important indicator of 
quality and maturity of fresh cherry (Esti et al., 2002). Phenolic antioxidants have many positive effects on the human health like anti-carcinogenic and anti-inflammatory effects which makes them important in nutrition (Usenik et al., 2008).Polyphenolics have been also demonstrated to have antiviral, antiallergenic, anticarcinogenic activities as well as beneficial effects on gut microbiome and epigenetic effects(Martin et al. 2013).

As far as we know, this is the first report of the antioxidant capacity and biochemical composition of sweet cherries grown under Moroccan climatic conditions. Thus, the main objective of this work was the determination of the variability of fruit weight, percentage of pulp, titratable acidity, maturity index, total phenolics, flavonoids and anthocyanins contents of fruit, as well as the antioxidant activity of fruits of four sweet cherry cultivars and to estimates the correlation between total phenolics and antioxidant activity.

\section{MATERIAL AND METHODS}

\section{Plant material}

Fruits were harvested in commercial orchards situated in tow locations of the Middle Atlas regions [("Toufselt" (Azrou) and "Laanoceur" (Sefrou)]. "Toufselt" valley is characterized by humid and temperate climate with an annual average temperature of $10.8^{\circ} \mathrm{C}$ and an average of rainfall higher than $600 \mathrm{~mm}$. The "Laanoceur" locality is characterized by a continental climate with cold winter and hot summer, with annual average of rainfall varied between 400 and $600 \mathrm{~mm}$ and an annual average temperature of $10.6^{\circ} \mathrm{C} .2$

Fruits of four sweet cherry cultivars ('Burlat', 'Van', 'Napoléon' and 'Cerisette') were randomly harvested at the optimum commercial maturity based on fruit maturity and color development during May and June 2014. Fruit samples $(0.5 \mathrm{~kg})$ were transferred to the pomology laboratory in National School of Agriculture of Meknes immediately after harvest for further fruit quality attribute measurements. To determine the total phenolic content, total anthocyanin content and total antioxidant activity, cherries were pitted manually, frozen in liquid nitrogen and then stored at $-20^{\circ} \mathrm{C}$ until the time of analysis.

\section{Chemicals and reagents}

1,1-Diphenyl-2-picrylhydrazyl (DPPH) and ABTS was from the Fluka company (Switzerland). Trolox (6-hydroxy-2, 5, 7, 8-tetra methylchroman-2-carboxylic acid), which is a hydrophilic analogue of vitamin E, Gallic were purchased from SigmaAldrich (St. Louis, MO, USA). 


\section{Phenotypic characteristics}

For each cultivar, twenty fruits were analyzed for physical characteristics. Fruit weight was measured on an electronic balance with a sensitivity weighingof \pm 0.01 gand randomly harvested 20 fruits from different parts of trees with four replications were used for measurement.. The percentage of pulp were calculated using the formula (Fruit weight-stone weight)/Fruit weight)*100.

\section{Titrable acidity, total soluble solids and maturity index of sweet cherry fruit}

The titrable acidity (TA) was determined by titration to $\mathrm{pH} 8.1$ using a digital $\mathrm{pH}$ meter (Thermo Orion 3 star) at $21^{\circ} \mathrm{C}$ with $0.1 \mathrm{M} \mathrm{NaOH}$ solution and expressed as $\mathrm{g}$ of malic acid per liter of juice (IFU, 1996). The instrument was calibrated to $0^{\circ} \mathrm{Brix}$ using distilled water (Giusti and Wrolstad, 2001).

The total soluble solids (TSS) were determined with a digital refractometer (Metteler-Toledo Gmbh, 30 PX, Switzerland, calibrated using distilled water). Results were reported as Brixat $21^{\circ} \mathrm{C}$.

Maturity index was calculated as the ratio between Total soluble solids and titrable acidity. The pulp of fruit, was obtained from extraction of juice from the five fruits of each cultivar taken at random and expressed as volume of juice per $100 \mathrm{~g}$ of fruits. The maturity index (MI) was calculated by dividing the total soluble solid with titrable acidity. The percentage of pulp were calculated using the formula (Fruit weightstone weight)/Fruit weight)*100.

\section{Preparation of sample and Biochemical parameters}

Ten fruits per sample were frozen at $-20^{\circ} \mathrm{C}$ and lyophilized (CHRIST ALPHA 1-4 LD plus) under vacuum, and $2 \mathrm{~g}$ of lyophilized fruit were introduced into a flask then $20 \mathrm{ml}$ of methanol was added. After 30 minutes of stirring, the mixture was centrifuged (6000 turn/ min, 15min) and kept in the dark until analysis.

\section{Total phenolic content (TP)}

The total phenolics were determined according to Slinkard and Singleton (1977). For $0.25 \mathrm{ml}$ of the sample extract $(1 / 10), 0.25 \mathrm{ml}$ of Folin-Ciocalteu reagent $(2 \mathrm{~N})$ and $2 \mathrm{ml}$ of distilled water were added and the mixture was stirred by vortex, then $0.25 \mathrm{ml}$ of sodium carbonate $(20 \% \mathrm{w} / \mathrm{v})$ was added. The extracts were mixed, stirred and then allowed to stand in the dark for 30min before measuring the absorbance at 750nm using a spectrophotometer (Safas UV-Visible spectrophotometer). All samples were prepared in triplicate. The results were expressed as $\mathrm{mg}$ gallic acid equivalent in $100 \mathrm{~g}$ dry weight (mg GAE/100g D.W). 


\section{Total anthocyanins content (TA)}

The TAC in sweet cherry extract was determined using the $\mathrm{pH}$ differential methods, with slight modifications Giusti and Wrolstad (2001).Briefly, $0.4 \mathrm{~mL}$ sweet cherry extract samples were taken, and one of them was adjusted to $10 \mathrm{~mL}$ with potassium chloride $(25 \mathrm{mM})$ buffer, $\mathrm{pH} 1.0$, and the other with sodium acetate $(0.4 \mathrm{M})$ buffer, $\mathrm{pH}$ 4.5. After equilibrium at $15 \mathrm{~min}$, the absorbance was measured at $510 \mathrm{~nm}$ and $700 \mathrm{~nm}$, respectively, using an UV/visible spectrophotometer (spectraphysic Jasco UV 1700, Japan). The TAC was calculated as milligrams of cyanidin-3-glucoside (C3G) equivalents (molar extinction coefficient 26,900).

The Absorbance (A) was expressed as follows:

$\mathrm{A}=\left[\left(\mathrm{A}_{520} \mathrm{~nm}-\mathrm{A}_{700 \mathrm{~nm}}\right)\right]_{\mathrm{pH} 1.0}-\left[\left(\mathrm{A}_{520} \mathrm{~nm}-\mathrm{A}_{700 \mathrm{~nm}}\right)\right]_{\mathrm{pH} 4.5}$ and $\mathrm{TAC}$ of fruit was presented as mg cyanidin-3-glucoside/100g (DW) of sweet cherry fruit and was determined using equation below:

$$
\mathrm{TAC}=(\mathrm{A} * \mathrm{MW} * \mathrm{~F} * 100) * 1 / \mathrm{MA}
$$

With: A: absorbance; MW: molecularweight (449.2 $\left.\mathrm{g} \mathrm{moL}^{-1}\right)$; F: dilution factor (10); MA: molarabsorptivity of cyanidin-3-glucoside (26.900).

\section{Total flavonoids content (TF)}

Total flavonoids were determined according to the method described by Lamaison and Carnat (1990). For $1 \mathrm{ml}$ of diluted sample, $1 \mathrm{ml}$ of aluminium chloride methanolic solution (2\%) was added and mixed with vortex. Rutin was used to make the calibration curve. $1 \mathrm{ml}$ of diluted sample was separately mixed with $1 \mathrm{ml}$ of $2 \%$ aluminium chloride methanolic solution. After incubation at room temperature for 15 $\mathrm{min}$, the absorbance of the reaction mixture was recorded at $430 \mathrm{~nm}$. Total flavonoids were expressed as $\mathrm{mg}$ of rutin equivalent/100g D.W (mg ER/100g D.W).

\section{Antioxidant activity}

\section{Radical scavenging activity assay (DPPH)}

Antioxidant activity was also determined using the DPPH (1.1diphenyl-2-picrylhydrazyl) method reported by Brand-Williams et al. (1995) with some modifications. This method aims the evaluation of the effect of free radical scavenging antioxidants on DPPH. Briefly, $0.1 \mathrm{ml}$ of the extract was mixed with $3.9 \mathrm{ml}$ of DPPH $(0.1 \mathrm{mM})$. The mixture is incubated in the dark for $60 \mathrm{~min}$ and then the absorbance was recorded at $515 \mathrm{~nm}$. Results are expressed as $\mathrm{mg}$ equivalent Trolox/100g D.W. 


\section{Antioxidant activity by the ABTS method}

Antioxidant activity was measured using an improved ABTS method as described by Re et al. (1999)method according to TEAC (Trolox Equivalent Antioxidant Capacity) The ABTS radical cation solution was prepared through the reaction of $7 \mathrm{mM}$ of ABTS $\bullet+$ (2,2'-azinobis (3-ethylbenzothiazoline-6-sulphonic acid)) and $2.45 \mathrm{~mm}$ potassium per sulphate, after incubation at $23^{\circ} \mathrm{C}$ in the dark for $12-16 \mathrm{~h}$. The ABTS solution wasthendilutedwith $100 \mathrm{mM}$ phosphate buffer $(\mathrm{pH}$ 7.6) to obtain an absorbance of $0.700 \pm 0.005$ at $734 \mathrm{~nm}$. ABTS solution $(3.9 \mathrm{~mL}$; absorbance of $0.700 \pm$ 0.005 ) was added to $0.1 \mathrm{~mL}$ of the extract sample and mixed vigorously. The reaction mixture was allowed to stand at $23^{\circ} \mathrm{C}$ for $10 \mathrm{~min}$ and the absorbance at $734 \mathrm{~nm}$ was immediately recorded. A standard curve was obtained using Trolox standard solution at various concentrations (ranging from 0 to $30 \mu \mathrm{m}$ ) in $80 \%$ methanol. The absorbance of the reaction samples was compared to that of the Trolox standard and the results were expressed in terms of Trolox equivalents (TE)/100g D.W of sweet cherry.

\section{Statistical analysis}

All statistical analyses were performed using the SAS2000 program (SAS Institute, Cary, NC, USA). Analysis of variance used the PROC GLM procedure to distinguish the genotype and location effect. The genotype factor was hierarchical to the factor location because the trees were not repeated between sites. To draw a general conclusion among the four cherry locations, the population was considered as a random effect (Steel and Torrie, 1960) Means was separated by Duncan's multiple range test (P $<$ 0.05). Pearson's correlation coefficients were calculated using the PROC CORR procedure.

\section{RESULTS AND DISCUSSION}

\section{Physical and physicochemical parameters determination}

The physical aspect of four sweet cherry fruits investigated is presented in figure 1 and Table 1 .The result shows that a some physicochemical properties of the four sweet cherry cultivars. Fruit weight of "Van" cultivar was significantly greater than that of the "Burat", "Napoléon" and "Cerisette" fruits. On the other hand, "Burlat" cultivar registered similar fruit weightto that of "Napoleon" cultivar. The weight of four sweet cherry cultivars "Burlat", "Van", "Napoleon", and "Cerisette" was 4.91, 5.79, 4.77 and $4.31 \mathrm{~g}$ respectively. Fruit weight of eight commercial cherry cultivars and four new selections (Prunus aviumL.) from the breeding program at Agriculture and Agri-Food Canada was between 8.8 and 14.5 g (Girard and Kopp, 1998). Our results were lower than those of commercial cherry cultivars. The percentage of pulp for "Van" fruits $(96.26 \%)$ was significantly greater than that of "Burlat" (96.09\%), "Napoleon" (4.77\%) and "Cerisette" (4.31\%) fruits (Table 1). It is important to indicate that consumers generally prefer sweet cherries with large pulp amounts (Pérez-Sánchez et al. 2010). 
The titratable acidity for "Napoleon" cultivar (8.6 eqmalic acid g/l of juice) was significantly greater than that of the "Burlat" (7.38 geq malic acid /1, "Van" (6.81 geq malic acid /1) and "Cerisette" $(6.71 \mathrm{~g} / 1$ malic acid) fruits. The titratable acidity values for "Burlat", "Van" and "Cerisette" cultivars were similar. "Cerisette" cultivar had significantly higher maturity index (2.26) compared to that of "Burlat" (1.86), "Van" (1.88) and "Napoleon" (1.44). Such differences in maturity index may be related to differences in maturity during fruit collection (Vavoura et al. 2015).


Figure 1. Morphological characteristic of Sweet cherry cultivars.

Table 1. Some physicochemical properties of the four sweet cherry cultivars.

\begin{tabular}{|l|l|l|l|l|}
\hline Cultivar & Fruit weight(g) & $\begin{array}{l}\text { Percentage of } \\
\text { pulp \% }\end{array}$ & $\begin{array}{l}\text { Acidity( e g Eqmalicacid } \\
\text { per liter of juice of fruit }\end{array}$ & $\begin{array}{l}\text { Maturity } \\
\text { index }\end{array}$ \\
\hline Burlat & $4.91 \mathrm{~b}$ & $96.09 \mathrm{ab}$ & $7.38 \mathrm{~b}$ & $1.86 \mathrm{~b}$ \\
\hline Van & $5.79 \mathrm{a}$ & $96.26 \mathrm{a}$ & $6.81 \mathrm{~b}$ & $1.88 \mathrm{~b}$ \\
\hline Napoleon & $4.77 \mathrm{~b}$ & $95.95 \mathrm{~b}$ & $8.60 \mathrm{a}$ & $1.74 \mathrm{~b}$ \\
\hline Cerisette & $4.31 \mathrm{c}$ & $95.08 \mathrm{c}$ & $6.71 \mathrm{~b}$ & $2.26 \mathrm{a}$ \\
\hline
\end{tabular}

\section{Biochemical parameters}

The total phenolics ranged from 305.99 to $306.67 \mathrm{mg}$ GAE/100g DW (Figure 2). The highest total phenolics content was recorded in the fruits of 'Napoléon' cultivar (306.67mgGAE/100gDW) and the lowest value was recorded for 'Van' $(305.99 \mathrm{mg}$ GAE/100gDW). The values of total phenolics content in this study were lower compared to those reported in the literature for others varieties. (Kim et al. 2005;Serra et al. 2011; Petković et al. 2014).In addition, the value of total phenolic content of sweet cherries varied from 78 to $500 \mathrm{mg}$ GAE /100 g DW.(Kim et al. 2005; Dragović-Uzelac 
et al. 2010). These differences may be due to the extraction method (Melicháčováet al. 2010). Other factors may explain these results such as genetic factors, environmental conditions and degree of maturity (Hegedüset al. 2013; Bravo, 1988; Goncalves et al. 2004).

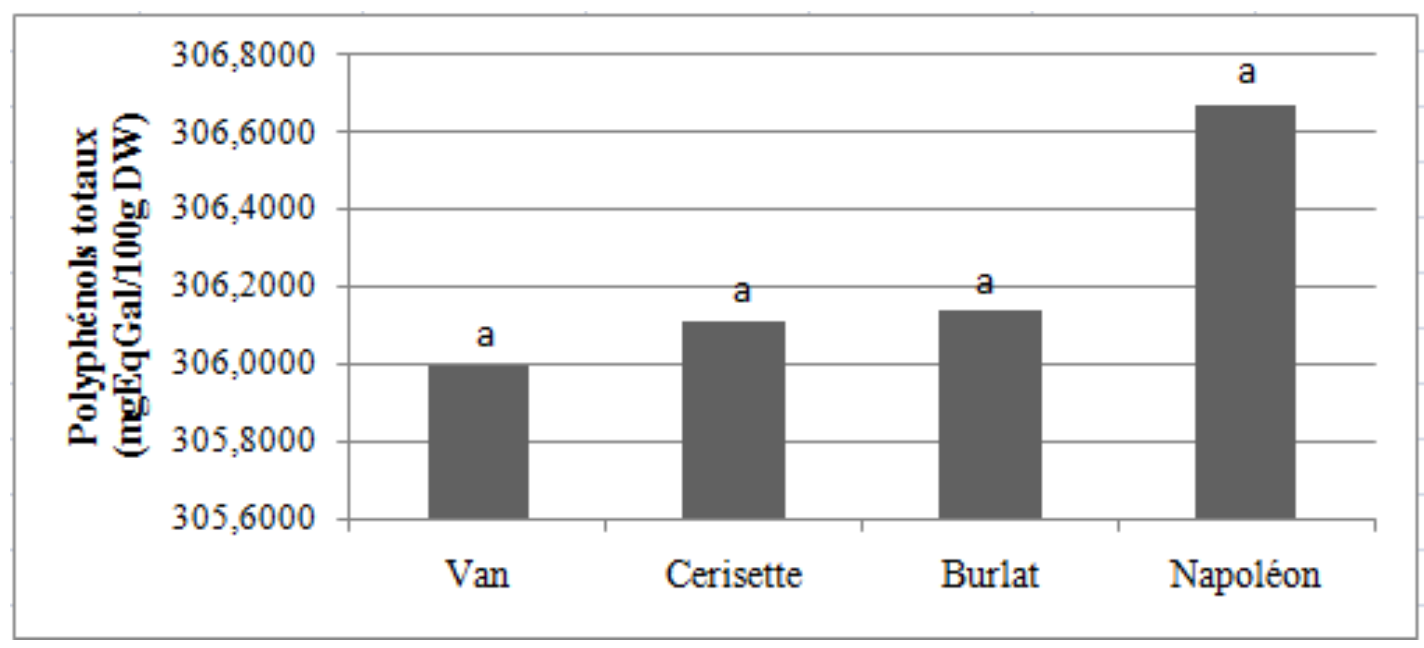

Figure 2. Total phenolics (TPC) in fruits of the four sweet cherry cultivars. The statistically significant difference among means was assessed by the Duncan test at $\mathbf{p}<0.05$. (*Values followed by the same letter are not significantly different at the $5 \%$ level).

Total flavonoids varied from 481.73-517.67 mg RE/100g D.W (Figure 3). These values are highest than those reported by Prvulovićet al. (2011) (42 to 154mg RE/100g D.W). The results showed significant differences for the total flavonoids content among 'Cerisette' and the remaining cultivars (Figure 3). The total flavonoids content was reported to be closely correlated with genotypes (Petkovićet al. 2014). The 'Cerisette' has the highest value of total flavonoids (517.67 RE mg/l00g D.W), while the lowest value was recorded in 'Burlat' (481.73 RE mg/ 100g DW) (Figure 3). Flavonoids were found to be an important part of human diet and are considered as active agent sin many medical plants (Martin et al. 2013). Flavonoids have been known to reduce oxidative stress in biological systems due to their antioxidant capacities (Kim et al. 2005). 


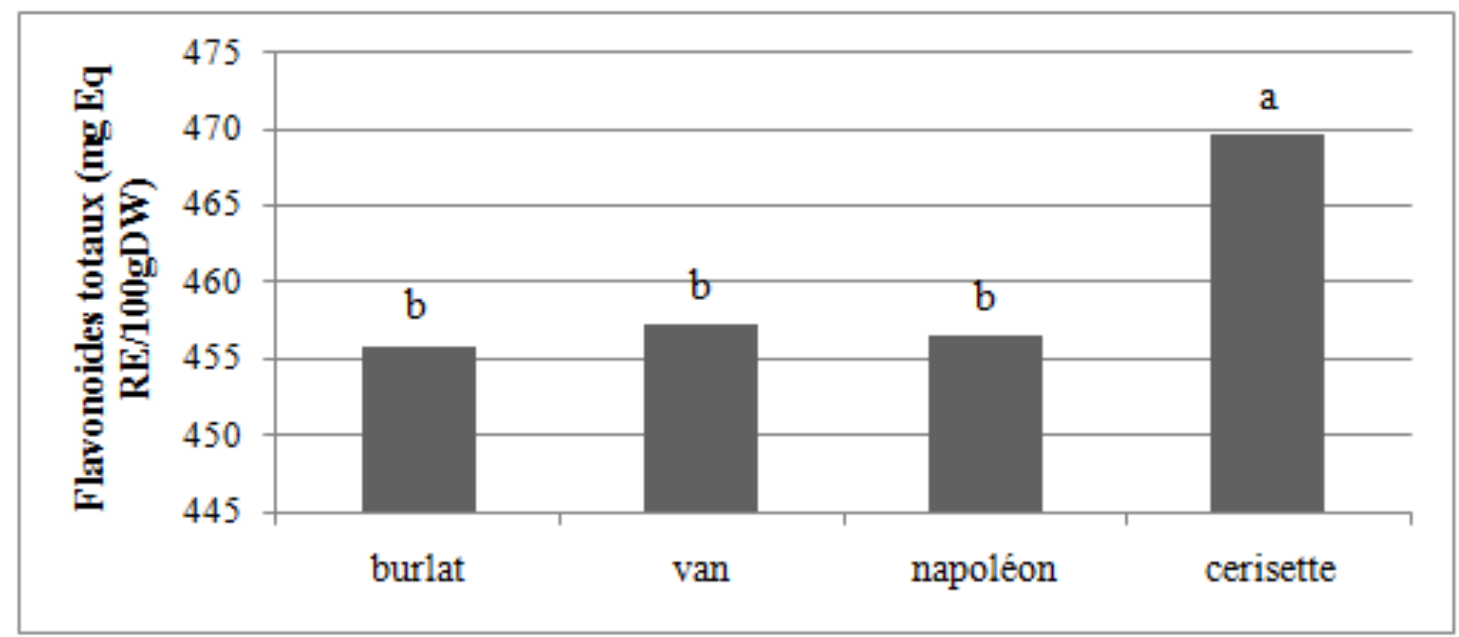

Figure 3. Total flavonoids of four sweet cherry cultivars. The statistically significant differences among means were tested by the Duncan test at $\mathbf{p}<0.05$. (*Values followed by the same letter are not significantly different at the $5 \%$ level)

The differences in total anthocyanins among the four sweet cherry cultivars were statistically significant (Figure 4). Total anthocyanin contents ranged from 1.09 and $2.89 \mathrm{mg}$ cyanidin 3-glucoside $/ 100 \mathrm{~g}$ D.W (Figure 4). The total anthocyanin concentration was reported to be ranged between 350 and $690 \mathrm{mg}$ cyaniding 3glucoside/100g D.W in some sweet cherry cultivars (Prvulović et al. 2011) which are higher than our results. These differences could be due to differences in methods of extraction (Vangdaland Slimestad, 2006). The highest value of total anthocyanin content was recorded in 'Burlat' cultivar (blackish colored fruit) and the lowest content of total anthocyanin content was in 'Napoléon' (yellow colored fruit). These results are in agreement with those reported by some authors (Vangdaland Slimestad, 2006; Karlidaget al. 2009) who reported that anthocyanin content was highest in cultivars with dark red color and lowest in cultivars with pale yellow color. The fruit of 'Burlat' was reported to contain very high total anthocyanins content (Useniket al. 2008; Prvulovićet al. 2011). However, some exceptional cultivars with high antioxidant capacity and relatively low anthocyanin content were also described (Hegedüset al. 2013). The anthocyanin content of fruit species is not stable and is influenced by environmental factors such as light and temperature. The growing conditions such as irrigation, plant density, fertilization, as well as the genotype characteristics also affect anthocyanin content of fruits (Karlidag et al. 2009). 


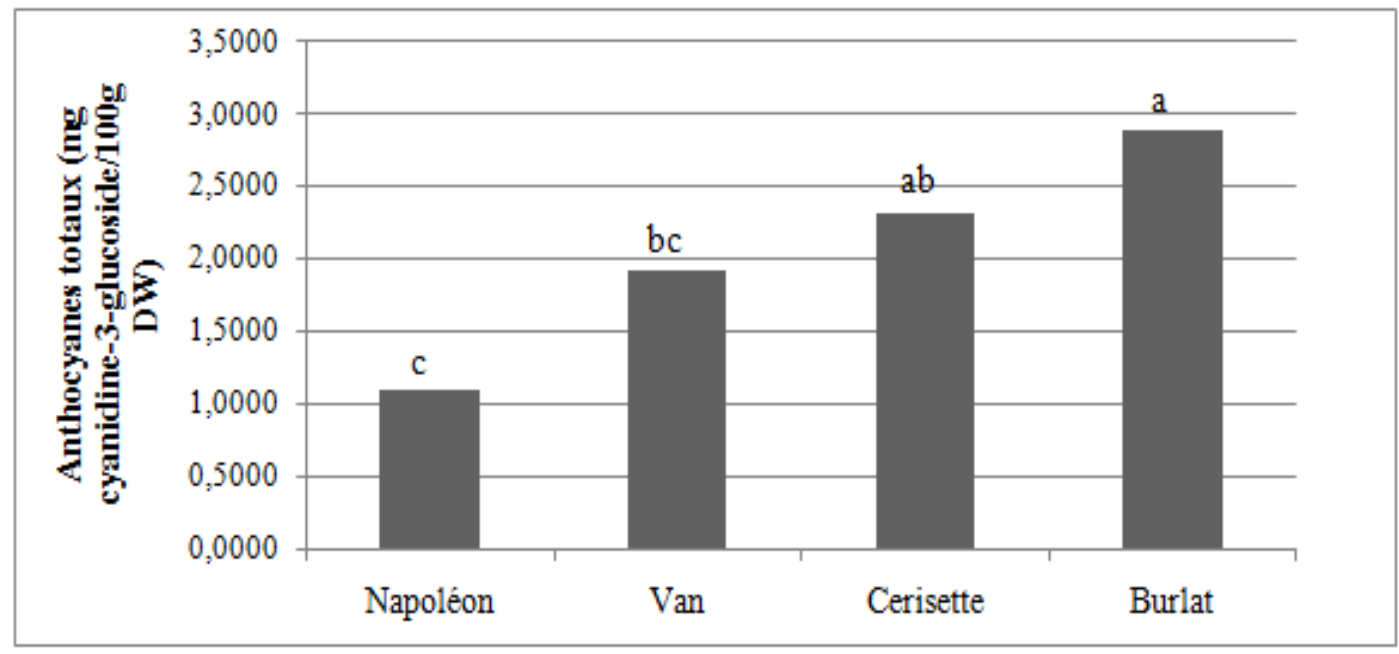

Figure 4. Total anthocyanins of the four sweet cherry cultivars. The statistically significant difference among means was assessed by the Duncan test at $p<0.05$. (*Values followed by the same letter are not significantly different at the 5\% level)

As the antioxidant capacity was measured by two methods namely, ABTS and DPPH assays. The ABTS assay is based on the generation of a blue / green ABTS, which is applicable to both hydrophilic and lipophilic antioxidant systems; whereas DPPH assay uses a radical dissolved in organic media and is, therefore, applicable to hydrophobic systems (Kim et al. 2002) Figure 5, resent the result of the antioxidant activities of sweet cherry cultivars. As can be seen the antioxidant activities (DPPH) (A) produce a less values of AA (DPPH) (17.18 to $18.11 \mathrm{mg}$ TRE./100g D.W) than ABTS assay, wich seemed to be a better method for expressing the antioxidant capacity of phenolic compounds in fruits sweet cherry. The values is ranged from 27.97 to 29.60 mg TRE/ D.W ABTS method (B) (Figure 5). Differences among cultivars were nonsignificant statistically (Figure 5). The highest antioxidant activity was observed in 'Burlat' cultivar $(18.11 \mathrm{mg}$ TRE/100g DW). The results are in agreement with those reported by Useniket al. (2008) who analyzed the antioxidant activity of 13 cherry cultivars showing the highest content in 'Burlat' cultivar. Moreover, several authors reported that the antioxidant activity of blackish colored fruit was higher than that in other genotypes, which agrees well with our results ('Burlat' cultivar has blackish colored fruit). (Karlidag et al. 2009; Vangdal and Slimestad, 2006; Battino et al. 2004). As reported by the litterature, the genetic factor is the first parameter with the potential to influence the antioxidant content in a commodity. Significant inter-cultivar variation in the phenolic content and antioxidant capacity has also been documented in cherries (Prvulović et al. 2012). The antioxidant activity is strongly influenced by the cultivation system, climatic conditions, duration and the technique of preservation of fruits (Sîrbu et al. 2012). Antioxidant capacity is also determined by the biochemical characteristics of each cultivar. The antioxidant capacity of sweet cherries is superior compared with apples or pears but has much lower values than species with small fruits such as the strawberry, raspberry or blueberry. (Battino et al. 2004; Serrano et al. 2005; Khanizadeh et al. 2009). 


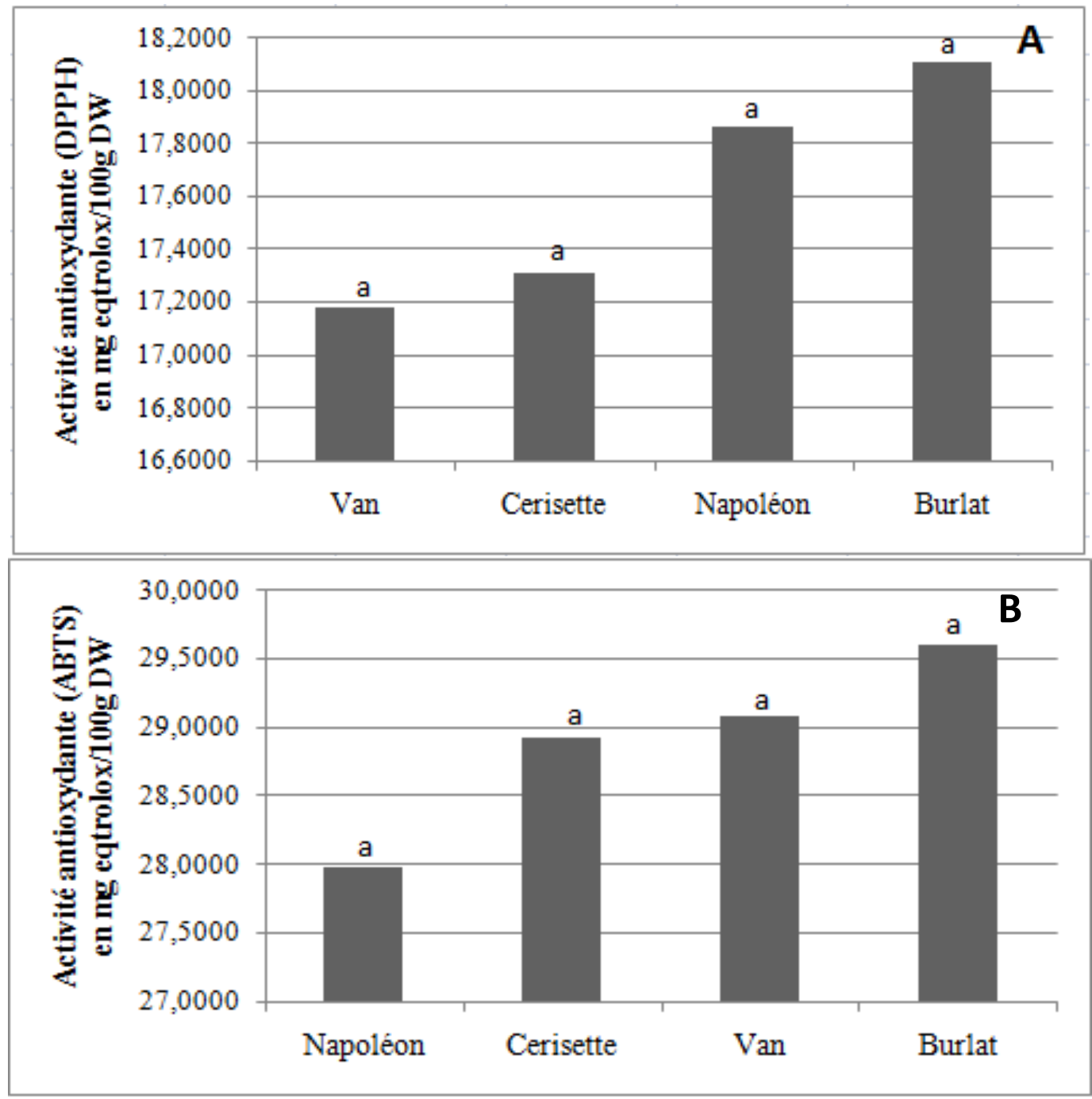

Figure 5. Antioxidant activity of the four sweet cherry cultivars by DPPH method (A) and ABTS method (B). The statistically significant difference among means was assessed by the Duncan test at $\mathbf{p}<0.05$. (*Values followed by the same letter are not significantly different at the $5 \%$ level)

The biochemical composition of four cultivars studied in "Toufselt" and "Laanoceur" is shown in figure 6. The analysis of variance showed no significant effect of the location on biochemical composition and antioxidant activity, except for the total anthocyanins content (Figure 6). The fruits collected from "Laancaeur" location contain more anthocyanins than those collected from Toufselft location. This difference is probably due to growing techniques. Irrigation by drip system at "Laanoceur" has probably positively affected the content of total anthocyanins. Generally, sweet cherries at "Toufselt" and "Laanoceur" regions have similar biochemical composition and antioxidant activity. 
A positive correlation was found between total polyphenols and antioxidant activity $(\mathrm{DPPH})(\mathrm{r} 2=0.73)$. Many studies have reported similar correlation between these variables (Chaovanalikit and Wrolstad, 2004; Vangdaland Slimestad, 2006; Karlidaget al. 2009; Damarand Ekşi, 2012). This indicates that the antioxidant activity closely depends on the total polyphenol content of cherry (Melicháčová et al. 2010; Prvulović et al. 2011; Giménez et al. 2014). *Values followed by the same letter are not significantly different at $\mathrm{p}<0.05$ level.

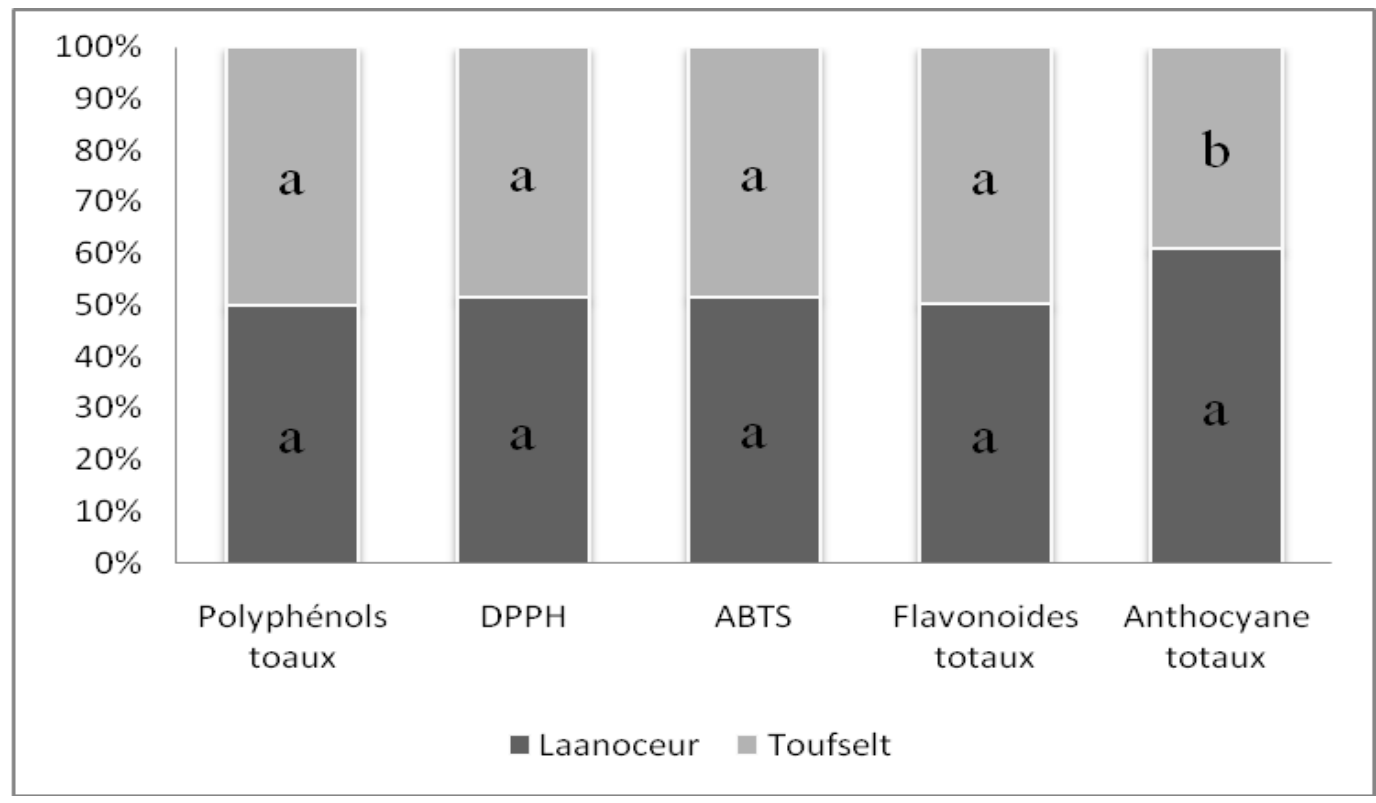

Figure 6. The biochemical composition and antioxidant activity of the four cultivars studied in "Toufselt" and "Laanoceur" locations. The statistically significant difference among means was assessed by the Duncan test at $p<0.05$. (*Values followed by the same letter are not significantly different at $\mathbf{p}<0.05$ level)

The statistical analysis showed no significant effects of the genotype and location on the total phenolics (Table 2). This might be explained by the low number of tested cultivars in this study. If many cultivars with diverse origin are compared, genotype becomes one of the most important factors in determining the antioxidant capacity of fruit (Hegedüs et al. 2013). Genotype effect is highly significant on total flavonoids ( $\mathrm{P}<0.01)$, confirming the results reported in the literature. (Karlidag et al. 2009; Xiaoet al. 2015). The total phenolics content is reported to be relative to the environment (Popescu et al. 2014). However, cultivar and location effects were not seen to be significant on the antioxidant activity in our study. The effect of location was significant on total anthocyanins $(\mathrm{P}<0.05)$. Geographical location probably had a strong impact on the anthocyanins content of different sweet cherry cultivars studied (Table 2). Also, the interaction of location with genotype showed significant differences in the total anthocyanin content. The total anthocyanins are determined by environmental factors 
(light and temperature) and growing conditions (irrigation, planting density and fertilization) (Karlidag et al. 2009).

Table 2. Genotype and agroecological effects on the biochemical characteristics of the fruit.

\begin{tabular}{|c|c|c|c|c|}
\hline Source of variation & Ddl & Mean square & F-value & $\operatorname{Pr}>\mathbf{F}$ \\
\hline \multicolumn{5}{|l|}{ Total phenolics } \\
\hline Location & 1 & 1.99 & 3.65 & 0.0616 \\
\hline Genotype (location) & 4 & 0.94 & 1.73 & 0.1576 \\
\hline Error & 52 & \multicolumn{3}{|l|}{0.54} \\
\hline \multicolumn{5}{|l|}{ Antioxidant activity } \\
\hline Location & 1 & 2.43 & 1.07 & 0.3047 \\
\hline Genotype (location) & 4 & 6.2 & 2.74 & 0.0384 \\
\hline Error & 52 & \multicolumn{3}{|l|}{2.26} \\
\hline Source of variation & DBL & Mean square & F-value & Pr $>F$ \\
\hline \multicolumn{5}{|l|}{ Total Flavonoids } \\
\hline Location & 1 & 322.14 & 0.7 & 0.4052 \\
\hline Genotype (location) & 4 & 2007.49 & 4.39 & 0.0039 \\
\hline Error & 52 & \multicolumn{3}{|l|}{457.43} \\
\hline Source of variation & DBL & Mean square & F-value & Pr $>\mathbf{F}$ \\
\hline \multicolumn{5}{|l|}{ Total anthocyanins } \\
\hline Location & 1 & 5.04 & 4.56 & 0.0374 \\
\hline Genotype (location) & 4 & 1.98 & 1.8 & 0.1436 \\
\hline Error & 52 & \multicolumn{3}{|l|}{1.1} \\
\hline
\end{tabular}

\section{CONCLUSION}

The relationship between antioxidant capacity and phenolic contents varied between Cultivars and strongly depends on total polyphenolic contents in fruits of four sweet cherrys and could be considered a good source of natural antioxidants. Sweet cherries at "Toufselt" and "Laanoceur" locations have similar biochemical composition and antioxidant activity, except for the total anthocyanins content that shows slightly elevated values at "Laanoceur". Geographic location in combination with higher precipitations influenced the fortified biosynthesis of anthocyanins in "Laanoceur" more than in "Toufselt" location. Therefore the agro-ecological conditions of the "Toufselt" and "Laanoceur" locations of the Middle Atlas have no effect on total polyphenol, flavonoids and antioxidant activity of sweet cherries produced in the Middle Atlas. If such an alteration is confirmed through several years, the identification of the factors behind elevated anthocyanins levels at "Laanoceur" may help to find growing techniques to increase anthocyanins content in cherry. The relationship between 
antioxidant capacity and phenolic contents varied between cultivars and strongly depends on total polyphenolic contents in fruits of sweet cherries and could be considered a good source of natural antioxidants.

\section{REFERENCES}

Battino, M. Scalzo, J. Capocasa, F. 2004. Fragole e antiossidanti: un primatonutrizionale. Frutticoltura. 66(4): 54-57.

Brand-Williams, W. Cuvelier, M. Berset, C. 1995. Use of a free radical method to evaluate antioxidant capacity. Food Sci Technol. 28(1): 25-30.

Bravo, L. 1998. Polyphenols: chemistry, dietary sources, metabolism and nutritional significance. NutriRev. 56(11): 317-333.

Chaovanalikit, A. Wrolstad, R.E. 2004. Total anthocyanins and total phenolics of fresh and processed cherries and their antioxidant properties. J of Food Sci. 69(1): 67-72.

Damar, I. Ekşi, A. 2012. Antioxidant capacity and anthocyanin profile of sour cherry (Prunuscerasus L.) juice. FoodChem. 135(4): 2910-2914.

Diaz-Mula, H. M. Zapata, P. J. Guillen, F. Martínez-Romero, D. Castillo, S. Serrano, M. Valero, D. 2009. Changes in hydrophilic and lipophilic antioxidant activity and related bioactive compounds during postharvest storage of yellow and purple plum cultivars. Postharvest BiolTechnol. 51(3): 354-363.

Dragović-Uzelac, V. Savić, Z. Brala, A. Branka, L. Danijela Bursać, K. Ante, B. 2010. Evaluation of phenolic content and antioxidant capacity of blueberry cultivars (Vacciniumcorymbosum L.) grown in the Northwest Croatia. Food Technol Biotechnol. 48(2): 214-221.

DRA. 2014. Direction Régionale de l'Agriculture De Meknès Tafilalt, Valorisation et commercialisation de la cerise d'Ain Leuh: Contraintes et perspectives.

Esti, M. Cinquanta, L. Sinesio, F. Moneta, E. Mateo, M. D. 2002. Physicochemical and sensory fruit characteristics of two sweet cherry cultivars after cool storage. Food Chemistry. 76(4): 399-405.

Giménez, M. J. Valverde, J. M. Valero, D. Guillen, F. Martinez-Romero, D. Serrano, M. Castillo, S. 2014. Quality and antioxidant properties on sweet cherries as affected by preharvest salicylic and acetylsalicylic acids treatments. Food Chem. 160: 226-232.

Girard, B. Kopp, T. G. 1998. Physicochemical characteristics of selected sweet cherry cultivars. Journal Agricultural and Food Chemistry. 46: 471-476.

Giusti, M. M. Wrolstad, R. E. 2001. Anthocyanins. Characterization and measurement of anthocyanins by UV-visible spectroscopy. In: Wrolstad RE, editor. In Current Protocos in Food Analytical Chemistry. New York; John Wiley and Sons Inc, Hoboken.

Goncalves, B. Landbo, A. K. Knudsen, D. A. P. Pereira, J. M. Rosa, E. Meyer, A. S. 2004. Effect of ripeness and postharvest storage on the phenolic profile of cherries (Prunus avium L.). J Agri. Food Chem. 52(3): 523-530.

Hegedűs, A. Taller, D. Papp, N. Szikriszt, B. Ercisli, S. Halász, J. Stefanovits-Bányai, É. 2013. Fruit antioxidant capacity and self-incompatibility genotype of 
Ukrainian sweet cherry (Prunus avium L.) cultivars highlight their breeding prospects. Euphytica. 191(1): 153-164.

IFU. 1996. Determination of titratable acidity. IFU Method No. 3. International Federation of Fruit Producers, Paris.

Karlidag, H. Ercisli, S. Sengul, M. Tosun, M. 2009. Physico-chemical diversity in fruits of wild-growing sweet cherries (Prunus avium L.). Biotech Biotechnological Equip. 23(3): 1325-1329.

Khanizadeh, S. Tsao, R. Rekika, D. Yang, R. DeEll, J. 2007. Phenolic composition and antioxidant activity of selected apple genotypes. J. Food Agric. Environ. 5(1): $61-66$.

Kim, D. O. Lee, K. W. Lee, H. J. \& Lee, C. Y. 2002. Vitamin C equivalent antioxidant capacity (VCEAC) of phenolicphyto chemicals. Journal of Agricultural and Food Chemistry. 50: 3713-3717.

Kim, D. O. Heo, H. J, Kim, Y. J. Yang, H. S. Lee, C. Y. 2005. Sweet and sour cherry phenolics and their protective effects on neuronal cells. J. Agric. Food Chem. 53(26): 9921-9927.

Kodad, O. En-Nahli, S. Hanine, H. EL Baji, M. 2016. Année exceptionnelle dans le moyen atlas: effets des aléas climatiques sur la floraison et sur la qualité du fruit du cerisier. Agric. Maghreb. 97: 62-63.

Lamaison, J. L. Carnat, A. 1990. Teneurs en principaux flavonoids des fleurs de Crataegeusmonogyna Jacq et de Crataegeuslaevigata (Poiret D. C) en fonction de la vegetation. Pharm Acta Helv. 65: 315-320.

Martinez-Romero, D. Alburquerque, N. Valverde, J. M. Guillén, F. Castillo, S. Valero, D. Serrano, M. 2006. Postharvest sweet cherry quality and safety maintenance by Aloe vera treatment: a new edible coating. Post-harvest Biol. Tec. 39(1): 93100.

Martin, C. Zhang, Y. Tonelli, C. Petroni, K. 2013. Plants, diet, and health. Annu Rev Plant Biol. 64: 19-46.

Melicháčová, S. Timoracká, M. Bystrická, J. Vollmannová, A. Čéry, J. 2010. Relation of total antiradical activity and total polyphenol content of sweet cherries (Prunus avium L.) and tart cherries (Prunuscerasus L.).Actaagric Slo. 95(1): 2128.

Naderiboldaji, M. Khadivi, A. Tabatabaeefar, A. Ghasemi Varnam khasti, M. Zamani, Z. 2008. Some Physical Properties of Sweet Cherry (Prunus avium L.) Fruit. American-Eurasian J. Agric. Environ Sci. 3(4):513-520.

Oukabli, A. 2004. Le Cerisier: une culture de haute altitude. Bull Trans de TechnolAgric. 116: 1-4.

Papp, N. Blázovics, A. Fébel, H. Salido, S. Altarejos, J. Fehér, E. Kocsis, I. Szentmihályi, K. Abrankó, L. Hegedűs, A. Stefanovits-Bányai, É. 2015. Antihyperlipidemic effects of sour cherries characterized by different in vitro antioxidant power and polyphenolic composition. Plant Foods Human Nutr. 70(4): 408-413.

Pedisic, S. Levaj, B. Dragovic-Uzelac, V. Škevin, D. Skendrović Babojelić, M. 2009. Color parameters and total anthocyanins of sour cherries (Prunuscerasus L.) during ripening. Agric. Consp. Scientificus. 74(3): 259-262. 
Pérez-Sánchez, R. Gómez-Sánchez, M. Á. Morales-Corts, M. R. 2010. Description and quality evaluation of sweet cherries cultured in Spain. J. Food Quality. 33(4): 490-506.

Petković, B. Matoš, S. Gorgi, N. Kukrić, Z. 2014. Analysis of antioxidant activity of different species of wild cherry (Prunus avium L.). Global Adv Res J Agric. Sci. 3(5): $128-135$.

Popescu, S. Velciov, A. B. Rivis, A. Costescu, C. Petolescu, C. 2014. Antioxidant Activity and Phenolic Content of Sweet Cherries (Prunus avium L.) From West and South-West of Romania. Food Sci. Techn. 71(2): 215-216.

Prvulović, D. Popović, M. Malenčić, Đ. Ljubojević, M. Ognjanov, V. 2011. Antioxidant Properties of Sweet Cherries (Prunus avium L.) - Role of Phenolic Compounds. World Acad. Sci. Engin. Technol. 59: 1149-1152.

Re, R. Pellegrini, N. Proteggente, A. Pannala, A. Yang, M. Rice-Evans, C. 1999. Antioxidant activity applying an improvised ABTS radical cation de colorization assay. Free Radical Biology and Medicine. 26: 1231-1237.

Seeram, N. P. Momin, R. A. Nair, M. G. Bourquin, L. D. 2001. Cyclooxygenase inhibitory and antioxidant cyanidin glycosides in cherries and berries. Phyto medicine. 8(5): 362-369.

Serrano, M. Guillen, F. Martinez-Romero, D. Castillo S. Valero, D. 2005. Chemical constituents and antioxidant activity of sweet cherry at different ripening stages.J Agric Food Chem. 53(7): 2741-2745.

Serra, A. T. Duarte, R. O., Bronze, M. R., 2011. Identification of bioactive response in traditional cherries from Portugal. Food Chemistry. 125(2): 318-325.

Sîrbu, S. Niculaua, M. Chiriţă, O. 2012. Physico-chemical and antioxidant properties of new sweet cherry cultivars from Iaşi, Romania. Agron. Res. 10(1-2): 341-350.

Slinkard, K. Singleton, V. L. 1977. Total phenol analysis: automation and 1117 comparison with manual methods. Am. J. Enol. Vitic. 28(1): 49-55.

Steel, R. G. D. Torrie, J. H. 1960. Principles and procedures of statistics. New York, Toronto, London; McGraw-Hill Book Company Inc; 481 p.

Usenik, V. Fabčič, J. Štampar, F. 2008. Sugars, organic acids, phenolic composition and antioxidant activity of sweet cherry (Prunus avium L.). Food Chemistry. 107(1): 185-192.

Vangdal, E. Slimestad, R. 2006. Methods to determine antioxidative capacity in fruit. $J$. Fruit Ornam Plant Res. 14(12): 123-131.

Varasteh, F. Arzani, K. Barzegar, M. Zamani, Z. 2012. Changes in anthocyanins in arils of chitosan-coated pomegranate (Punicagranatum L. cv. Rabbab-e-Neyriz) fruit during cold storage. Food Chemistry. 130(2): 267-272.

Vavilov, N. I. 1951. The Origin, Variation, Immunity and Breeding of Cultivated Plants. Soil Sci. 72(6): 482.

Vavoura, M. V. Badeka, A. V. Kontakos, S. Kontominas, M. G. 2015. Characterization of Four Popular Sweet Cherry Cultivars Grown in Greece by Volatile Compound and Physicochemical Data Analysis and Sensory Evaluation. Molecules. 20: 1922-1940

Vinson, J. A. Su, X. Zubik, L. Bose, P. 2001. Phenol antioxidants quantity and quality in foods: fruits. J. Agric. Food Chem. 49(11): 5315-5321. 
Xiao, Z. Fang, L. Niu, Y. Yu, H. 2015. Effect of cultivar and variety on phenolic compounds and antioxidant activity of cherry wine. Food Chemistry. 186: 69-73. 